\title{
CrimRxiv
}

\section{Does Third-Party}

Intervention Matter? A

\section{Video-Based Analysis of}

the Effect of Third-Party

Intervention on the

Continuation of

Interpersonal Conflict

Behaviour

\section{Peter Ejbye-Ernst}

Published on: Feb 16, 2022

DOI: $10.21428 / \mathrm{cb} 6 \mathrm{ab} 371.8 \mathrm{cbafd} 98$

License: Creative Commons Attribution 4.0 International License (CC-BY 4.0). 
